\title{
Corncob-derived Porous Carbon as an Interlayer Coating to Improve the Performance of Lithium Sulphur Battery
}

\author{
Zhigang Xu, Zhen Geng, Guanghai Yi, Chen Chen, Mingzhe Xue ${ }^{*}$, Bing Li, Cunman Zhang ${ }^{*}$ \\ Clean Energy Automotive Engineering Center, School of Automotive Studies, Tongji University, \\ Shanghai, 201804, China \\ *E-mail: mzxue@tongji.edu.cn, zhangcunman@tongji.edu.cn
}

doi: $10.20964 / 2017.05 .49$

Received: 14 February 2017 / Accepted: 23 March 2017 / Published: 12 April 2017

\begin{abstract}
Porous activated carbon derived from corncob without further element-doping was employed as a coating interlayer on polypropylene (PP) separator in lithium sulphur (Li/S) battery. The highly electrically conductive activated carbon served as a pseudo current collector dramatically reducing the interface resistance and thus improved the reaction kinetics of the cell system. Furthermore, the mirco/mesoporous structure and large pore volume of activated carbon provided an excellent environment to trap soluble polysulfide intermediates resulting in shuttle reaction and buffered the volume change of sulphur during cycling, prominently alleviating capacity fading. The cell with activated carbon coating layer maintained a high reversible specific capacity of $839.8 \mathrm{~mA} \mathrm{~h} \mathrm{~g}^{-1}$ after 100 cycles at a current rate of $0.3 \mathrm{C}\left(1 \mathrm{C}=1672 \mathrm{~mA} \mathrm{~g}^{-1}\right)$, comparing to $496.7 \mathrm{mAh} \mathrm{g}^{-1}$ of the cell with only pristine PP separator. Extended cycle life test exhibited a discharge capacity of $648 \mathrm{mAh} \mathrm{g}^{-1}$ after 350 cycles under $0.5 \mathrm{C}$. Moreover, thickness influence of activated carbon coating layer indicated that a thin layer of $29 \mu \mathrm{m}$ coating was sufficient enough to improve the electrochemical performance of Li/S battery. Thicker coating was only able to slightly improve the performance of battery.
\end{abstract}

Keywords: activated carbon, interlayer, Li/S battery, thickness

\section{FULL TEXT}

(C) 2017 The Authors. Published by ESG (www.electrochemsci.org). This article is an open access article distributed under the terms and conditions of the Creative Commons Attribution license (http://creativecommons.org/licenses/by/4.0/). 